\title{
Leiomioma esofágico*
}

\author{
Drs. CARLOS CÁRCAMO I. ${ }^{1}$, JORGE LAVANDEROS F. ${ }^{1}$
}

I Instituto de Cirugía, Facultad de Medicina, Universidad Austral de Chile, Valdivia. Chile.

\section{Esophageal leiomyoma}

Mujer de 62 años con antecedentes de Esclerodermia, dentro del estudio de su enfermedad de base se solicita tomografía computada de tórax que evidencia leve estasia esofágica en la mitad superior y presencia de un discreto aumento de volumen de partes blandas a nivel de la carina traqueal. Endoscopia evidencia una zona solevantada a $25 \mathrm{~cm}$ de la arcada dentaria superior (ADS) con mucosa de aspecto normal (Figura 1), radiografía contrastada de esófago evidencia a nivel de la carina traqueal una impresión esofágica de contornos romos que no causa disminución de calibre significativo y pudiera corresponder a una compresión extrínseca o a un tumor submucoso del tercio medio del esófago (Figura 2). Endosonografía evidencia lesión hipoecogénica homogénea, entre los 25 y $28 \mathrm{~cm}$ de la ADS de 3 x $1,7 \mathrm{~cm}$, que se ubica en la capa muscular propia, compatible con Leiomioma.

Se realiza una enucleación tumoral esofágica videotoracoscópica, sin lesionar la mucosa, la que impresiona de aspecto normal (Figura 3 A, B, C, D). La histopatología informa un tumor fusocelular de aspecto benigno con hallazgos altamente sugerentes de Leiomioma (Figura 4) y la inmunohistoquímica con marcadores que confirman dicho diagnóstico (SMA y desmina positivos).

Los tumores benignos del esófago son poco frecuentes y representan menos del $2 \%$ de las neoplasias de este órgano, hay una gran variedad histológica dependiendo de la estructura de la pared esofágica en que se originen; siendo el Leiomioma el más frecuente de ellos ${ }^{1}$. La mayoría son asintomáticos, de crecimiento lento, ubicados en el tercio medio y distal; en general no comprometen toda la circunferencia de la pared. Se vuelven sintomáticos tardíamente, siendo la disfagia el síntoma eje $\mathrm{e}^{2}$.

El tratamiento de estos tumores continúa siendo motivo de controversia, parece existir consenso en que se deben extirpar en pacientes sintomáticos ${ }^{3}$. Los Leiomiomas que son asintomáticos o pequeños pueden ser evaluados con imágenes en forma periódica cada 1 ó 2 años.

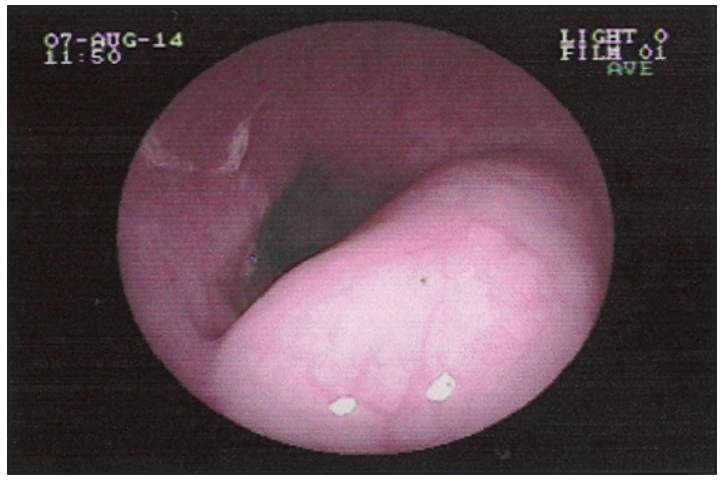

Figura 1. Endoscopia digestiva alta.

* Recibido el 20 de abril de 2012 y aceptado para publicación el 28 de mayo de 2012.

Los autores no refieren conflictos de interés.

Correspondencia: Dr. Carlos Cárcamo I.

Simpson 850. Subdepartamento de Cirugia Adultos. Hospital Regional Valdivia. Chile. ccarcamoi@gmail.com 

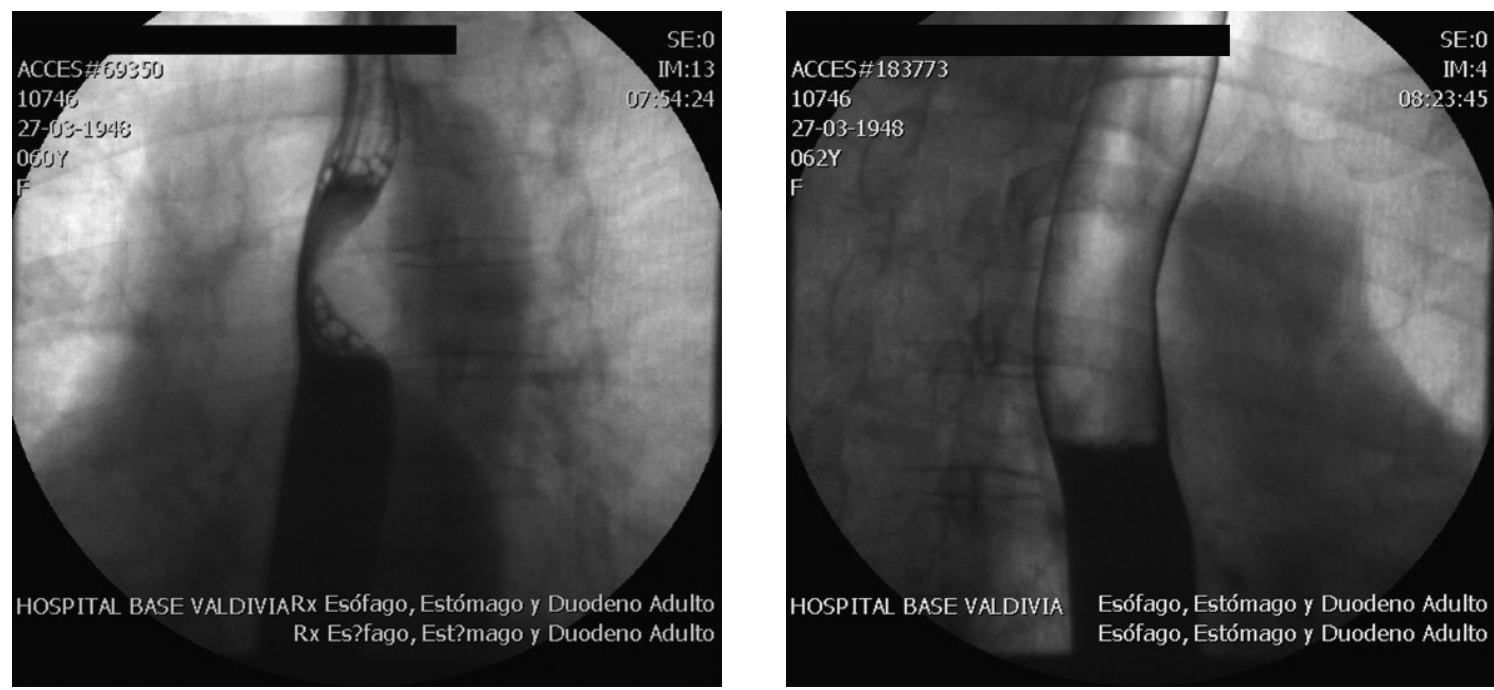

Figura 2. Radiografía contrastada de esófago (caso clínico). Izquierda: imagen preoperatoria; Derecha: imagen postoperatoria.
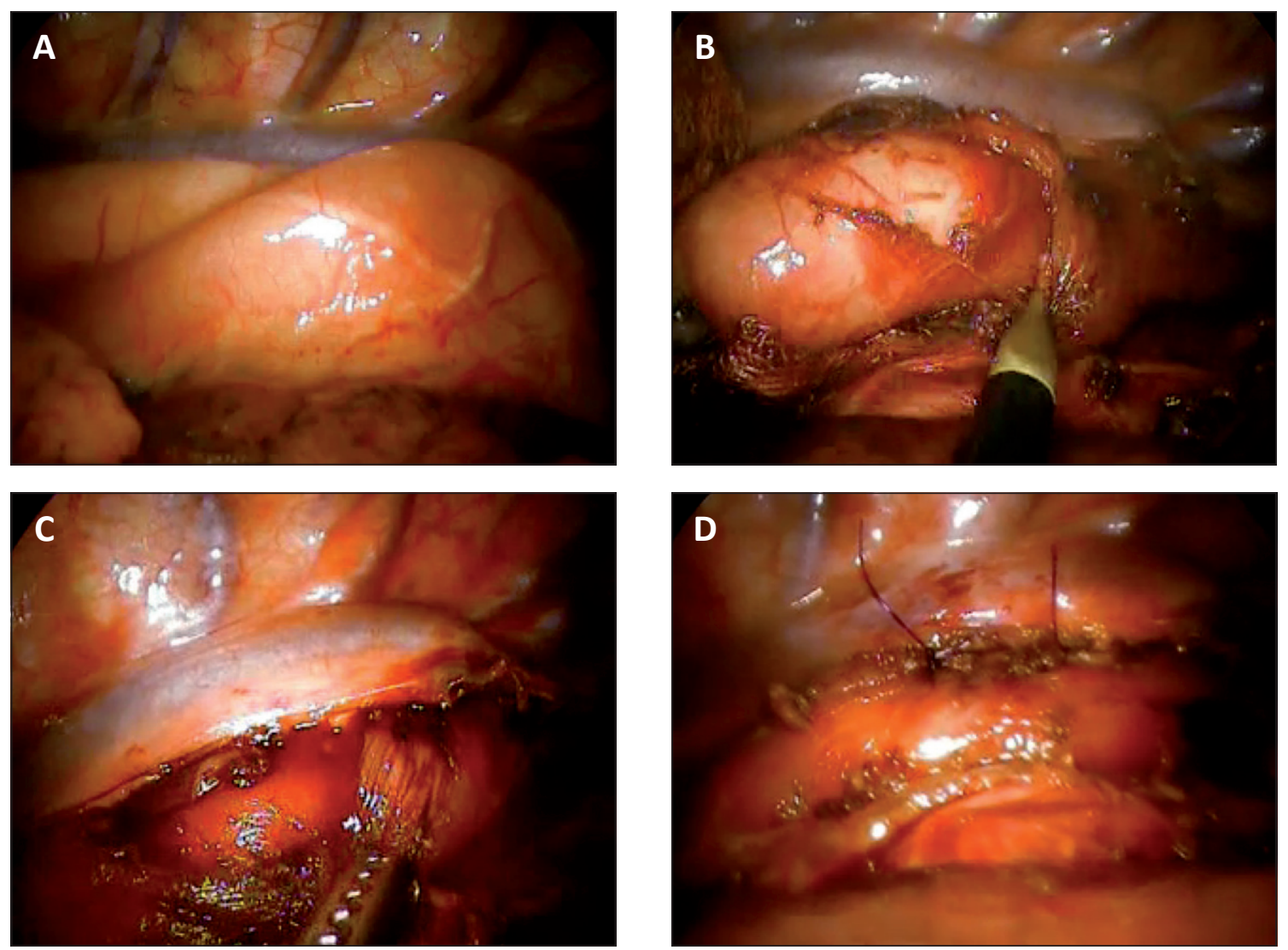

Figura 3. Imágenes cirugía. A: Tumor in situ. B: Escisión quirúrgica. C: Mucosa indemne postenucleación. D: Visión final. 


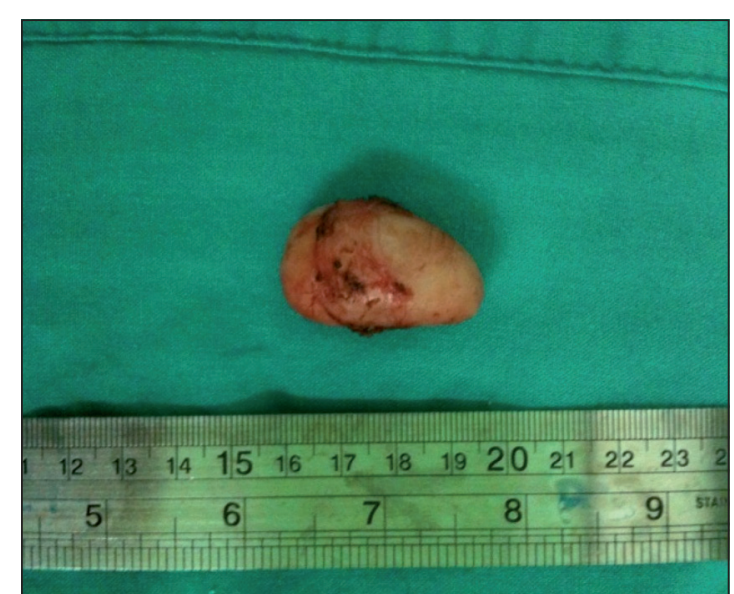

Figura 4. Pieza quirúrgica.

La escisión quirúrgica se recomienda en los leiomiomas sintomáticos, mayores de $5 \mathrm{~cm}$, cuando hay ulceración de la mucosa y para establecer el diagnóstico histológico definitivo ${ }^{4,5}$. Al momento de plantear una resolución quirúrgica se debe considerar el tamaño, la localización y la morfología del tumor; siendo la enucleación extramucosa el tratamiento de elección; en aproximadamente el $10 \%$ de los casos se requiere una esofagectomía ${ }^{6,7}$.

\section{Referencias}

1. Lawrence S, Singhal S, Brinster C, Marshall B, Kochman M, Kaiser L, et al. Current Management of Esophageal Leiomyoma. J Am Coll Surg. 2004;198: 136-46.

2. Choong C, Meyers B. Benign Esophageal Tumors: Introduction, Incidence, Classification, and Clinical Features. Seminars in Thoracic and Cardiovascular Surgery 2003; 15:3-8.

3. Galindo, Mazano, De La Torre; Tumores Benignos de Esófago. Enciclopedia Médica Americana. Cirugía Digestiva 2006;I-180, Pág. 1-8.

4. Xuan Zhu, Xiao-Qian Zhang, Bi-Min Li, Ping Xu, Kun-He Zhang, Jiang Chen. Esophageal Mesenchymal Tumors: Endoscopy, Pathology and Immunohistochemistry. World J Gastroenterol. 2007;13:768-73.

5. Priego P, Lobo E, Rodríguez G, Alonso N, Gil Olarte M.A, Pérez De Oteyza J. Tratamiento Quirúrgico del Leiomioma Esofágico: Análisis de nuestra Experiencia. Rev Esp Enferm Dig. 2006;98:350-8.

6. Levine M. Benign Tumors of the Esophagus: Radiologic Evaluation. Seminars in Thoracic and Cardiovascular Surgery 2003;15:9-19.

7. Rice T. Benign Esophageal Tumors: Esophagoscopy and Endoscopic Esophageal Ultrasound. Seminars in Thoracic and Cardiovascular Surgery 2003;15:20-6. 